DOI: 10.23860/JMLE-2019-11-2-7

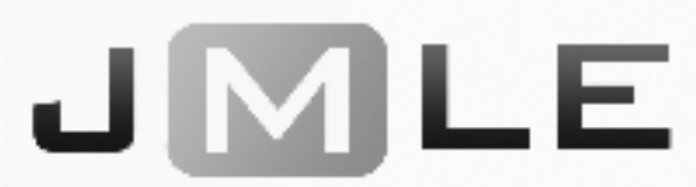

The National Association for Media Literacy Education's

Journal of Media Literacy Education, 11(2), 122 - 145

\title{
Faith Leaders Developing Digital Literacies: Demands and Resources across Career Stages According to Theological Educators
}

\author{
Kyle M. Oliver \\ Teachers College, Columbia University \& Virginia Theological \\ Seminary, USA \\ Stacy Williams-Duncan \\ Curry School of Education, University of Virginia \& Virginia \\ Theological Seminary, USA
}

\begin{abstract}
Despite popular framings about skills for 21st-century jobs, there are few studies of how new media literacies unfold in workplaces, nor of how professional education programs can build on adult learners' previous experiences to foster effective digital communication practices. We argue that seminaries and divinity schools are a particularly rich context in which to explore these questions. Not only do theological education students represent an unusually wide spectrum of ages compared to graduate programs across professional education, but ministry leadership also lends itself to a sociocultural understanding of digital literacy in which past work-related interpersonal skills are likely to be relevant. This paper revisits data from an interview-based study of theological educators that identified seven Digital Literacies for Ministry. In this new analysis, we use a demandsresources model from workplace psychology to explore and interpret how adult students across career stages engage with these literacies, identifying and illustrating from instructor interview data, and from our own interactions with students, strengths and challenges for each age group. The paper concludes with implications for theological education and other areas of media literacy education in professional schools.
\end{abstract}

Keywords: media literacy, digital literacy, theological education, professional education, religious leadership, adult digital literacy, digital literacies for ministry

Robust literatures explore a range of perspectives on digital literacy and how new media skills and practices may impact young people's futures as learners, friends, workers, and citizens (e.g., Jewitt, 2005; Lankshear \& Knobel, 2008; Jenkins, Purushotma, Weigel, Clinton, \& Robison, 2009; Vasudevan, 2010; Mitchell, 2011; Price-Dennis, Holmes, \& Smith, 2015). Given the popular and 
sometimes scholarly tendency in K-12 and higher education to frame this issue in terms of job skills for future employment (e.g., Martin \& Grudziecki, 2006; Voogt, Erstad, Dede, \& Mishra, 2013; Kivunja, 2014) it is surprising how little we attend to digital literacy among working adults and its practice and impact in their work.

The first studies germane to this issue were inquiries into the age-related "digital divide" understood to be separating older and younger students. Prensky (2001) described this divide as between digital natives and digital immigrants. Subsequent interrogation of the often vague ways this claim was taken up yielded critiques on both conceptual and empirical grounds (Bayne \& Ross, 2007; Bennett \& Maton, 2010; Brown \& Czerniewicz, 2010; Jones, Ramanau, Cross, \& Healing, 2010). These publications were marked in part by a shift from claims about access and immersion to claims about specific activities and abilities (Bennett \& Maton, 2010). Although various experience and skills gaps exist across age and generational cohorts (Livingstone \& Helsper, 2007; van Deursen \& van Dijk, 2011; Friemel, 2016; Schreurs, Quan-Haase, \& Martin, 2017), it seems increasingly clear that "experience with technology, and not age, accounts for the observed lifelong changes in digital literacy skills" (Eshet-Alkalai \& Chajut, 2009, p. 713).

Still, not all digital literacy skills are created equal. We note with van Dijk (2005) that digital literacy spans a spectrum of skills that run from operational (device use) to navigational (understanding structures) to informational (searching and interpreting) to strategic (meeting personally meaningful objectives). He and van Deursen (2011) later found that age correlated to differences in operational and navigational skills but not informational or strategic ones. Relatedly, Eshet-Alkalai and Chajut (2009) found that over a five year period, a group of adults aged 30 to 40 improved significantly and nearly closed the skill gap between themselves and a group of high school and college students when it came to "tasks that emphasize experience and technical control." For "tasks that emphasize creativity and critical thinking" the older adults performed much better from the start and widened the gap over time due to their improvement and in some cases the younger participants' decreased performance (p. 715).

Results like these stand in contrast to common narratives about the relationship between age and digital skills and point to the reality that digital literacy is about more than manipulating technology tools. We believe this reality comes into focus when we consider how digital literacy functions in specific professional contexts. A useful touchstone here is Martin and Grudziecki's (2006) definition of digital usage as "competence within specific professional or domain contexts" within the European Digital Literacy Framework:

Each user brings to this exercise his/her own history and personal/professional development. Digital usages are thus shaped by the requirements of the situation. The drawing upon digital competence is determined by the individual's existing digital literacy and the requirements of the problem or task. (p. 257, italics ours)

Against this backdrop, a focus on experience rather than age makes sense. Indeed, we might through this new focus expect results that show age gaps closing 
or reversing for skills that have less to do with the technology per se than with the strategic recruiting of resources for contextually specific outcomes. These outcomes are likely to be shaped as well by "analog" wisdom users bring to bear. Recent treatments of professionally motivated deployment of digital literacy include studies of the ability to shape the public image of social workers and the people they serve (Cubbage, Gillians, Algood, \& Ramsey, 2017), improve nurses' ability to support patients developing health-related media literacy (Herzberger, 2008), and change prescribing behavior among medical students from marketingto evidence-based practices (Corbin et al., 2018).

\section{Context of the Study}

This article leverages data from a recent interview-based research project and from our own teaching experience to explore these dynamics at play in a context of new media literacy learning in which we are both deeply invested and experienced. It continues our investigation of a framework for media literacy education in a small but interesting corner of professional education: students preparing for religious leadership. Lay and ordained leaders of faith communities receive training "in the disciplined analysis of sacred texts; in the formation of their ... identities, dispositions, and values; in the understanding of the complex social, political, personal, and congregational conditions that surround them; and in the skills of preacher, counselor, liturgist, and leader through which they exercise their ... responsibilities" (Foster, Dahill, Golemon, \& Tolentino, 2006, pp. xi-xii).

Students in theological education are serving in rapidly changing social contexts and institutional circumstances (Putnam, 2000; Rainie \& Wellman, 2012; Pew Research Center, 2015). Although so-called pedagogies of contextualization are a key component of theological curricula (Foster et al., 2005), a survey of Association of Theological Schools (ATS) member websites identified few faculty and programs that were publicly transparent about addressing the social changes brought about by new media cultures (Oliver, Kimball, Williams-Duncan, \& Blanchard, 2016). This absence is alarming given that media and religion scholars are documenting the increasing prevalence of digital and hybrid sites and modes of religious expression, practice, and belonging (Cheong, 2011; Campbell, 2012; Pew Research Center, 2014).

Seeking to respond to how a complex digital world has changed their disciplines is one of several commonalities theological educators share with others in higher education. Indeed, seminary educators such as Hess (2005), Lytle (2013), Zsupan-Jerome (2014), Copeland (2015), and the team at Virginia Theological Seminary with whom we have been teaching and conducting research have integrated secular media theories and educational approaches into our work.

For the purposes of this special issue in media literacy education for all ages, an important difference between theological education and other fields is that students of ministry leadership skew significantly older and have a wider range of ages than their graduate professional school counterparts (see Table 1), even after a recent drop from a student body age plateau during the period of 1993-2001 (Association of Theological Schools, 2006). 
Table 1

Recent Average Student Age in U.S. Graduate Professional School Programs ${ }^{1}$

\begin{tabular}{ll}
\hline Program & Age \\
\hline Medicine & 26 \\
Nursing $^{2}$ & 33 \\
Law $^{3}$ & $<30$ \\
Social Work & 31 \\
Business (Executive MBA) & 38 \\
Ministry & $\mathbf{3 9}$ \\
All Graduate & 32 \\
All Master's & 32 \\
All Professional Doctorate & 27 \\
\hline
\end{tabular}

Figure 1 shows the age distribution in ministerial leadership programs recently reported by ATS $(2018$, p. 45). In theological education, students tend to pursue the professional doctorate degree after serving for some time as lay or

\footnotetext{
${ }^{1}$ Estimated from or directly reported in data released by Association of American Medical Colleges (all students, 2017-2018), National League for Nursing (master's students, 2015-2016), Council on Social Work Education (master's students, 2015), Executive MBA Council (2018), ATS (basic and advanced ministerial leadership students, 2017-2018), and National Center for Education Statistics (all graduate students, all master's students, all professional doctoral students; 2015-2016). The ATS includes Canada, and the Executive MBA Council is a global organization.

2 The nursing estimate would likely have been a year or two higher if it included students studying for the professional doctorate, as it does for ministry (estimated average age of nursing doctoral students: 41).

${ }^{3}$ Neither the American Bar Association nor the Association of American Law Schools reports student age information; an extensive but not exhaustive review of U.S. law school websites found none with average ages of 30 or more.
} 
ordained leaders in ministry settings, having completed the master's level credential before doing so. Thus, students 35 and older are more likely than their early-career counterparts to have full-time faith leadership experience. Still, middle- and late-career students make up nearly half (47\%) of enrollees in the master's level programs. Further complicating how we understand these age and experience dynamics is the fact that many older students pursuing formal training may nevertheless have been serving faith communities in volunteer or paid positions for many years. For the purposes of this article, this age diversity in theological education represents an opportunity to explore how past experience shapes learning needs with respect to domain-specific digital literacy skills or tasks.

Figure 1. Ages of enrolled ministerial leadership students (U.S. \& Canada, fall 2017).

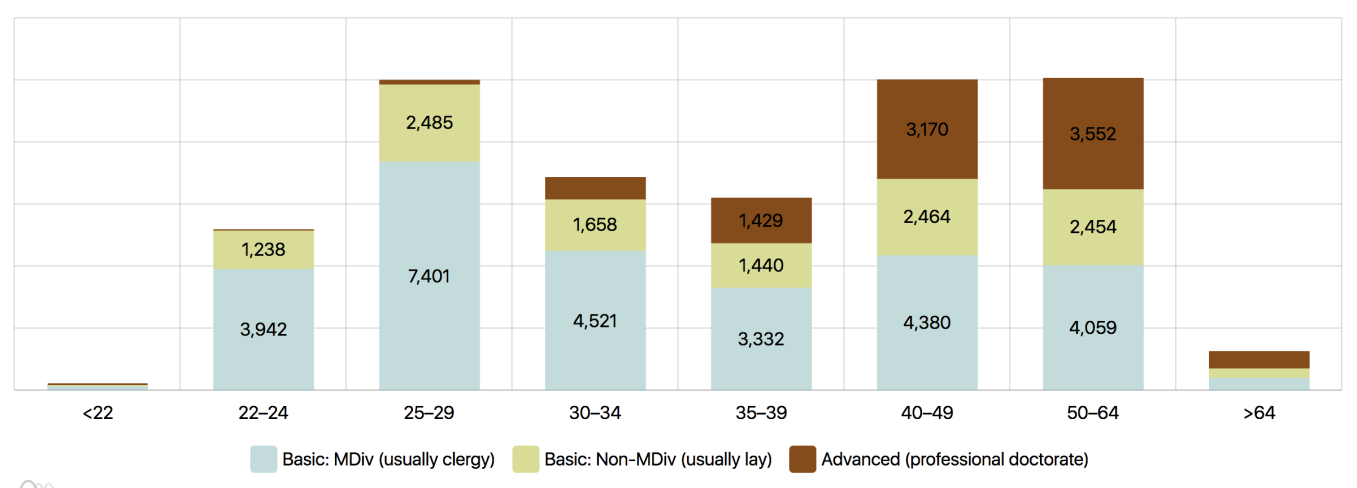

\section{Conceptual Framework}

Our previous analysis of the interview data we return to in this article, together with subsequent development work with a subset of our study participants, led to the construction of a domain-specific framework consisting of seven digital literacies theological educators are seeking to help their students develop (Oliver, Williams-Duncan, \& Kimball, 2019). Table 2 gives the names and definitions of these Digital Literacies for Ministry (DLM), as well as shorthand abbreviations used in this article. They represent a consensus about what religious leaders need to know and be able to do in order to minister within digital and hybrid spaces by using new media tools. 
Table 2

Names and Definitions of the Digital Literacies that Comprise the Framework

Name of literacy

(abbreviations

Definition

boldface)

Navigating hybrid \& digital cultures

Convening hybrid \& digital community

Cultivating a spiritually wise digital habitus (centering)

Maintaining a posture of experimentation (experimenting)

Creating \& curating faith-based media artifacts

Connecting media theory to theological reflection (reflecting)

Presenting authentically \& pastorally online the ability to move with confidence through relevant spaces and communities online

the ability to bring together groups online and help them flourish as communities

the ability to apply the insights of spiritual traditions to the daily practice of digitally mediated social participation

an orientation for exploring new tools, trying out strategies, tolerating and learning from apparent failures, and innovating in a fast-changing landscape

the ability to find or make and then share appropriate resources to teach faith and prompt reflection

the ability to reflect on new media theory and practice from a theological perspective and on religious belief and practice from a media studies perspective

the ability to explore, claim, and "inhabit" appropriate traits of religious leadership

Source: Oliver, Williams-Duncan, \& Kimball, 2019

The perspective represented in this previous work understands literacy as a highly contextual social practice for participating in distinct cultures and communities. It also recognizes the "spatial turn" in scholarly conceptions of literacy (see Oliver, 2019; following Leander \& Vasudevan, 2009; Vasudevan, 2010). In a sense, the insight of that turn is at the core of why theological educators are interested in digital literacy: if people of faith are "doing" religious community and expression both in person and online (Campbell, 2012), then leaders need to recognize how both kinds of context are "an ongoing process and practice deeply tied up with the word" (Sheehy \& Leander, 2004, p. 3). More concretely: A faith or faith-adjacent Facebook group, Twitter hashtag, website, or Zoom conference is not empty or neutral space that gets filled with religious meanings and relating- 
any more than is a house of worship. The medium may not be the message, but it significantly shapes the message.

However, the sociocultural perspective on digital literacies also points to an important continuity: the digital skills our participating instructors identified as important for their students are closely related to skills ministry trainees have always developed. Skills for healthy leadership, relationship, and communication take on a particular character in digital and hybrid spaces, but many of the same principles apply. Moreover, many seminarians were encouraged to pursue formal ministry training precisely because their communities identified their interpersonal facility and sensitivity. Older students, though perhaps still somewhat less likely to have developed the digital dimension of these skills, are likely through life and work experience to have developed the aspects of the skills that have little to do with technology per se.

\section{Theoretical Framework}

Our analysis of "ages and stages" in theological education requires a way of understanding each group that avoids over-generalized assumptions and reified categories. Since neither ministry nor technological sophistication maps neatly onto age, we believe learners from any professional or personal background can build on their past experience to become effective "digital ministers" and in the process develop a better understanding of their challenges. Our desire to honor the experiences of students of different ages without engaging in a reductionist approach to categorization led us to analyze our data using Salmela-Aro and Upadyaya's (2018) synthesis of (1) a "life-span approach" to understanding adult worker development with (2) the job demands-resources model (JD-R) for understanding worker motivation, performance, and health.

Like related balance models (demand-control, effort-reward), JD-R is a theory from occupational psychology that examines opposing forces in workers' day-to-day activity:

Job demands refer to those physical, psychological, social, or organizational aspects of the job that require sustained physical and/or psychological (cognitive and emotional) effort or skills ... Job resources refer to those physical, psychological, social, or organizational aspects of the job that [contribute to] achieving work goals[,] [r]educe job demands and the associated physiological and psychological costs[, or] [s]timulate personal growth, learning, and development. (Bakker \& Demerouti, 2007, p. 312, italics ours)

In his comprehensive review of research using the JD-R model, Schaufeli (2017) found it to be a well-developed and yet flexible model that can effectively be applied in a wide range of work environments to address a variety of research objectives. Salmela-Aro and Upadyaya (2018) used this model to study trends in engagement and burnout for early-, mid-, and late-career workers, which they defined as those younger than 35 years old, 35-49 years old, and 50 years or older, respectively. They took into account professional demands and resources as well as 
personal ones. For example, late-career adults are more likely to have wellestablished networks of colleagues (professional resource) and to be caretakers for aging parents (personal demand). The researchers' analysis showed that work demands related to both interpersonal relationships and the use of information and communications technology were greater during the early- and mid-career phases than the late-career phase.

Our interest in Salmela-Aro and Upadyaya's work is not their research methodology or their findings per se but rather the benefits of a lifespan view of JD-R theory for understanding diverse adult workers. Recognizing that particular stages in life tend to be associated with patterns of demands and resources in individuals' lives helps us strike a balance between the equally problematic extremes of assumed age determinism and "age-blindness." Moreover, the demands-resources paradigm encourages us to think expansively about how, say, a second-career minister entering seminary later in life nevertheless brings substantial resources from past work and life experience and may rapidly come to have as much in common with same-age colleagues who were ordained young than with the younger colleagues with whom the older person studied (Nesbitt, 1995; Nichols, 2018; cf. Malony \& Hunt, 1991). Considering both professional and personal demands and resources is also especially helpful in this context, since "non-standard work schedules, long work hours, the helping nature of the profession, and numerous but varied responsibilities" lead ministers to experience "boundary ambiguity between the domains of work and family" (Wells, Probst, McKeown, Mitchem, \& Whiejong, 2012, p. 216). Ministry leadership is a wholeperson endeavor, and our theoretical understandings of ministers' professional capacities should be shaped accordingly.

\section{Research Question \& Objective}

Thus equipped with a set of professionally contextualized digital literacy skills or tasks from the original analysis of our interview data and with a theoretical framework for better noticing, understanding, and accounting for strengths and challenges adult learners of all ages and career stages bring to their learning and practice, we returned for this article to our interview data set with a new research question:

RQ: How do the digital literacy learning experiences of ministry leadership students vary according to age and career stage?

Our primary objective in asking this question is to begin to identify strategies for improving these learning experience for both older and younger students. Although it will be most directly useful to ministry educators, this exploratory analysis serves as a rare study of a systemic framework for media literacy education in a professional context and should be of interest to educators working with adult learners of any age. Our findings suggest a pedagogical strategy of building on strengths and previous knowledge, in contrast to predominant discourses that simultaneously bring many older students to our digital media course much more focused on their deficits than their assets while obscuring for 
some of our younger students the fullness of the sociocultural learning opportunities before them.

\section{METHODOLOGY}

\section{Study Design}

When we began our work studying digital media skills in the professional context of ministry leadership education, we chose qualitative methods for their ability to explore phenomena not yet well described in our fields of practical theology and the study of theological education. Wishing to clarify simultaneously what "digital media for ministry" might mean in the context of ministerial leadership preparation and practice as well as how our colleagues were helping students foster such engagement, we designed a semi-structured interview protocol that asked our colleagues (1) what digital media skills they believed were important for their students in their present and future work, (2) how these instructors and their institutions were helping their students develop these skills, and (3) what kinds of student attitudes and responses they had observed in their teaching - including variation by demographic factors. The analysis that led us to identify the literacies themselves (Oliver et al., 2019) emerged from coding and subsequent informant feedback about the "what skills?" questions, but those literacy codes were then applied to the remainder of the transcripts in order to identify all the places in the interviews where these skills were discussed. It is from this coded data set that we began the analysis this article reports.

To supplement this interview data, as well as to incorporate insight from our own reflexive practice as instructors in this field and to provide a form of qualitative triangulation, we also decided to include in our research activities an exercise of prompted recall followed by the construction of case studies from analysis of student artifacts from four past sections of the Digital Media for Ministry course we have taught ${ }^{4}$ since 2015 . In effect, we planned to check our findings from the interview data against our own experiences working with students - not as definitive or systematic confirmation, but as a means of strengthening our confidence in the findings by illustrating them with rich classroom data.

\section{Recruitment \& Sampling}

We recruited interview participants via email during the 2015-2016 school year. We began with a key informant sampling strategy (Bradburn, Sudman, \& Wansink, 2004), identifying seminary faculty and other theological educators who had published in this area, attended our digital media for ministry professional development conferences, or were otherwise known to us as having an active interest and expertise in the relationship between new media and the practice of ministry. We then incorporated a two-fold snowball sampling strategy (Noy, 2008), asking participants both at the time of our initial contact and during the interview

\footnotetext{
${ }^{4}$ Both together and with other co-instructors.
} 
itself to recommend others we should talk to. All interviewees who agreed to participate completed our informed consent process.

We did not originally conceive of our Digital Media for Ministry course as a venue for research. Thus, as one of us had done previously when engaging in now-published reflective instructor research about this innovative course (Oliver, 2019), when preparing this manuscript we first reviewed past course rosters as a way to jog our memory about the 67 students we have taught in the four past sections of this course. We then wrote to the three students we identified in this prompted recall activity as having experiences that were illustrative of the findings of our interview data analysis (see below). These former students, all of whom had graduated at the time of our contacting them, gave their written permission for us to review and excerpt their course artifacts for the purpose of this article. The difficulty of finding and then obtaining such consent from a larger number of the students we have taught prevented us from conducting a more systematic analysis. ${ }^{5}$

\section{Data Collection}

Oliver interviewed our original 36 participants from 13 ministry training organizations in 19 separate interviews during the 2015-2016 school year. In Table 3 , we have numbered these participants 1 through 36 according to the order in which they were interviewed. The approximate interview dates are given, as well as a short descriptor of the various institutional contexts where the participants served. The interviews were audio recorded, lasted 45-90 minutes, and took place in person (15 interviews) or via video conference (4 interviews). All interviews were transcribed by a social science transcription firm and later coded using the Dedoose cloud-based data analysis tool.

Five of the interviews (of participants 2-6, 15-21, 22-27, 28-29, and 30-31) took place in focus group format rather than as one-on-one conversations. In each case, the focus group format allowed all the would-be participants from a given context who were interested in participating to do so within the time constraints of the researcher's travel schedule. It is possible that the logistical decision to allow for focus group interviewing shaped the data we collected from these participants, both by potentially shortening the total "air time" a given speaker could claim, or through interpersonal effects leading to overly convergent responses or peer-based social desirability bias (Hollander, 2004). Oliver attempted to mitigate the former effect by requesting longer sessions when interviewing groups and by probing for additional contributions before moving on to the next question in the protocol. The latter risk is of course more difficult to mitigate, though in our view it was counterbalanced by the benefits of focus group interaction, including the potential for one participant's response to elicit reflections that others might not have

\footnotetext{
${ }^{5}$ In our ongoing study of DLM development across the seminary curriculum, we are partnering with faculty colleagues in other courses to proactively collect student artifacts, subject to informed consent from the outset rather than years after the course.
} 
considered, and to allow for the joint exploration of particular topics in cases of collaboration.

For the course artifact review and case study construction process, we collected the relevant students' weekly homework assignments and final projects from our teaching records. These assignments included our instructor feedback.

Table 3

Interview Participant Overview

\begin{tabular}{ll}
\hline Participant \# (interview date) & Context \\
\hline 1 (Sept 2015) & 2 southern universities \\
35 (online - April 2016) & 3 midwestern seminaries \\
$2-6$ (Oct 2015) & \\
$8-9$ (Oct 2015) & \\
$10-11$ (Oct 2015) & \\
12 (online - Nov 2015) & midwestern university \\
7 (Oct 2015) & 2 northeastern universities \\
13 (online - Dec 2015) & \\
14 (Feb 2016) & \\
36 (online - May 2016) & Denominational ethnic ministries office \\
$15-21$ (April 2016) & 3 western seminaries \\
$22-27$ (April 2016) & \\
$28-29$ (April 2016) & \\
$30-31$ (April 2016) & western university \\
32-34 (April 2016) &
\end{tabular}

\section{Analytical Procedures}

For our new analysis of the interview data, Oliver reviewed and recoded all 318 excerpts that had been originally coded as representative of one or more of the DLM. This preliminary recoding identified 45 excerpts (14\%) that mentioned age, life-stage, generations, etc., in some way that was relevant to the literacy. A more critical review of each of these excerpts led to the elimination of approximately half of them from this analysis. In most of the excluded excerpts, the participants' mentioning of age addressed the potential audience ministry leaders need to reach and serve, not the age or life-stage of the ministry students themselves. In other cases, the interview participants were referring in these excerpts to undergraduate religious studies (non-ministry) students they also teach. 
After completing this recoding and consistency checking, Oliver examined the 23 remaining excerpts for themes, focusing on the excerpts related to each literacy. We then reviewed these emergent themes together, using Salmela-Aro and Upadyaya's (2018) life-span approach to JD-R to interpret and interrogate them. The results of this procedure form the basis of our findings and discussion section below.

Finally, we brought each theme to the prompted recall procedure we described above. This allowed us to identify possible student experiences to serve as illustrative case studies of the themes we identified from our colleagues' impressions of their own students' experiences. We reviewed all the weekly assignments and course projects of the students we identified and wrote the illustrative case studies together. In choosing excerpts to be included in constructing the case studies, we were careful to remove potentially identifying information such as names and specific details about the students' ministry contexts.

\section{FINDINGS \& DISCUSSION}

Of the 23 literacy-related excerpts (7\%) that explicitly mentioned the age or life-stage of the learner as relevant, 6 of the 7 literacies were represented. The most frequently mentioned literacy for which age or life-stage was cited as relevant was navigating hybrid and digital cultures (16 excerpts). The literacy for which the largest percentage of excerpts cited age or life-stage as relevant was maintaining a posture of experimentation (6 of 30 total excerpts). Participants in 10 of the 19 interviews identified age or life-stage of the ministry student as relevant to at least one of the DLM, and of the 6 literacies represented, all were cited in multiple interviews. The distribution of excerpts recoded via this procedure is summarized in Table 4.

Table 4

Frequency and Percentage of Code Co-occurrence: DLM and Age-related

\begin{tabular}{llll}
\hline Literacy & $\begin{array}{l}\text { Number of } \\
\text { excerpts that } \\
\text { relate this } \\
\text { literacy to age }\end{array}$ & $\begin{array}{l}\text { Percentage of } \\
\text { this literacy’s } \\
\text { excerpts that } \\
\text { relate it to age }\end{array}$ & $\begin{array}{l}\text { Number of } \\
\text { interviews that } \\
\text { relate this } \\
\text { literacy to age }\end{array}$ \\
\hline $\begin{array}{l}\text { Navigating hybrid \& } \\
\text { digital cultures }\end{array}$ & 16 & $13 \%$ & 4 \\
$\begin{array}{l}\text { Convening hybrid \& } \\
\text { digital community }\end{array}$ & 2 & $5 \%$ & 2 \\
$\begin{array}{l}\text { Cultivating a spiritually } \\
\text { wise digital habitus }\end{array}$ & 3 & $14 \%$ & 3 \\
$\begin{array}{l}\text { Maintaining a posture of } \\
\text { Mang }\end{array}$ & 6 & $20 \%$ & 4
\end{tabular}


experimentation

$\begin{array}{llcr}\begin{array}{l}\text { Creating \& curating faith- } \\ \text { based media artifacts }\end{array} & 0 & 0 \% & 0 \\ \begin{array}{l}\text { Connecting media theory } \\ \text { to theological reflection }\end{array} & 3 & 3 \% & 3 \\ \begin{array}{l}\text { Presenting authentically \& } \\ \text { pastorally online }\end{array} & 4 & 11 \% & 3\end{array}$

Obviously, only a small subset of excerpts coded for each literacy explicitly mentions age or life-stage as relevant. Since our research did not specifically ask participants to address age, ${ }^{6}$ we should not take this small percentage as a strong statement for or against the idea that this factor would be important. Still, the level of agreement across interviews in light of the small sample is encouraging. We found two coherent themes among the recoded excerpts, relevant to four of the DLM.

Theme 1: Late-and mid-career students are more likely than early-career students to find the navigating and experimenting literacies most demanding

The most pronounced theme that emerged from this analysis is that older students may find it difficult to navigate hybrid and digital cultures, which is consistent with more general digital divide findings reporting an age gap in favor of younger students in matters closely related to navigation and technical control (Eshet-Alkalai \& Chajut, 2009; van Deursen \& van Dijk, 2011). Older students are often aware of these struggles, and it can contribute to a sense of anxiety in their learning. The anxiety may be exacerbated by the fact that this is one of the more technical of the literacies, requiring (in part) a familiarity with a variety of hardware and software.

A typical example is this assessment by Participant 30 of late-career students" ability to navigate online: "For some older people, you need almost a laminated card with 'this is what you do in order to get on ${ }^{7}$ to FaceTime or Skype." She went on to elaborate that this challenge can make teaching older students especially challenging in online courses:

$[\mathrm{H}]$ ow do we train people who are frankly scared of computers to take a course on the computer through the computer? We're not near

\footnotetext{
${ }^{6}$ The occasion of this special issue prompted us revisit our data and "make due" with what we have available in order to explore what we believe to be an important and under-studied question in both theological education and MLE in professional contexts.

${ }^{7}$ In this and subsequent quotations, we have sometimes added italics for emphasis.
} 
them. How do we teach them how to use it when they have to get on a computer even to learn how to use it? That's the challenge. They're like, "Can't you come in person and teach us?" Actually, no, because you're really all far away and dispersed. We end up talking people through it on the phone. It's very time consuming.

A mini-historical analysis by Participant 10 helps show how this age-related navigational challenge is connected to the literacy of experimentation:

I still have enough seminarians who are second- and third-career people who, like me, grew up in an era in which-I mean I went to college with an electric typewriter. ${ }^{8}$ When computers first came in, you had to type command-line stuff. You worried because if you typed it wrong, you could wipe out something ... Kids growing up in this space don't have that kind of fear and they've learned how to experiment.

Participant 36 cited experience similar to Participant 30's of needing to offer additional support to some mid- and late-career students, and like Participant 10 he used a comparison to younger students' lived fluency. However, he framed the latter contrast in a positive light:

Many of my older students were quite clear with themselves that they didn't know what they were doing, and that they had a learning curve when it came to digital environments and digital skills ... $[\mathrm{T}]$ hat created a certain kind of need in terms of me doing a bit of handholding and helping them, being patient with that and receiving quite a few emails about playing technical support.

At the same time, it was really refreshing, because there was a newfound - a beginner's mind about it ... I think sometimes when you're so native to the place, it can be hard to go back and be told that you need some tools.

These three accounts can be better understood when considered through the lens of stage-oriented JD-R theory. Late- and mid-career students often recognize their lack of technical experience with digital platforms. They are aware that professional demands of navigating hybrid and digital cultures for the sake of effective ministry leadership outstrip the personal and professional resources they have developed in the past. Unlike many younger students - for whom a playful

\footnotetext{
${ }^{8}$ This participant models a helpful concreteness that moves beyond a vague notion of "digital immigration" and cites a specific consequence of how older students' personal learning histories intersect with technology's developmental trajectory.
} 
willingness to learn by doing itself serves as a resource - they may be initially uncomfortable simply experimenting with the technology until they can perform the necessary tasks. Still, by being assertive about the demands before them and by leveraging available resources (instructor support, use of more familiar communication technology), they can find appropriate supports to skill development.

Finally, note that Participant 22 hypothesizes that personal and professional life experience may serve as a better resource than late- and mid-career students are able to identify, at least initially:

There seem to be students that come in, there's a number of them who often say that they don't know how to function in a world that has a little bit more technology than what they're used to. Even though if they talk about it, they're on Facebook. They're tweeting. They're posting pictures. They're uploading. They're using Dropbox. They're attaching documents to email...

When they jump back into education - many of them have been away - they are not able to connect those skills that they already have and use them here, which is fascinating. Many of them are in a workplace where they're required to do those things or they use it in personal matters. Then, they go here and they're like "Where do I click? I don't know what's happening. Train me."

This instructor's observation points to a possible limitation of interpreting late-career ministry formation experiences in light of JD-R theory in cases where someone is changing jobs or contexts. Here the older students seem to be unaware of the resources they have (professional and/or personal experience with common technology tasks and practices) and how these can be applied to meet the demands of their new context. They struggle to recognize the relevance and to transfer past experience to the novel context of theological education or ministry practice. If we want to use the JD-R model to understand mid- or late-career students, we need to remember that the corpus of past experiences consciously accessible to them as resources may begin small, especially during their earliest days in a new role and context. We can help them make those connections more explicit.

As we thought back on our experiences with students, this theme resonated with the story of a pair of students on the older end of Salmela-Aro and Upadyaya's (2018) mid-career designation. We will pseudonymously call them Cynthia and Terri. Cynthia sometimes expressed frustration that the course did not provide 
enough technical training. ${ }^{9}$ Moreover, she made it clear that she disagreed with several of the very premises of the class and did not really want to be there. ${ }^{10}$ Terry came to the class with a professional background in technology but a desire to learn to further contextualize these skills in ministry settings.

Their end-of-semester work ended up being quite strong. The pair teamed up for the final project, producing a video piece each seemed to find personally meaningful. Their proposal for the project received the highest marks in the class and made clear that each understood (contra Participant 22) how to contribute from where their past experience from other fields was strongest and most applicable, but on tasks that nevertheless allowed them each to learn something new. The feedback Oliver and his co-instructor offered on their final production commented in particular on "the technological learning curve [they] worked through" (recall Participant 10's comment above) as well as their "collaboration and work ethic."

In short, Cynthia in particular did seem to find the navigating and experimenting literacies challenging, as have many though not all of the mid- and late-career students we have worked with in Digital Media for Ministry. But Cynthia and Terri together were also highly adept at identifying and leveraging their significant and complementary professional resources to meet the demands of this digital media project. Although we did not have the life-span JD-R framework in mind when we wrote the project proposal requirements for this course, we are especially grateful that we prompted students to explain how their project would "support [their] development as church leaders," since for Cynthia and Terri this prompted explicit positioning and negotiation of their past experiences relative to present learning goals.

Theme 2: Early-career students are more likely than mid-and late-career students to find the convening and reflecting literacies most demanding

\footnotetext{
${ }^{9}$ For example, "This course seemed to assume that the student had more of a pre-existing knowledge of various digital media tools ... My expectation of the class was that it would be more of a 'how' to use digital media, than it was on the importance of and best uses of digital media."

${ }^{10}$ A comment on one of her assignments led Oliver to believe she felt pressured to take the course in a way reflective of this observation from research Participant 22: "The older students are saying, 'I've gotta learn and adapt to stay employed, to get employed." Her critical attitude came with sharp insight into the ethical implications and socioeconomic disparities of new media access and use. Her pushback in the course seems especially prescient as we write this in December of 2018, and was highly integrated with her theological values in a way we have rarely observed with younger students.
} 
The second major theme to emerge from the age-related analysis was that while younger students may navigate and experiment more easily, the ability to lead in and reflect on digital settings can be especially challenging for this age group. Here again, our domain-specific findings seem to be in agreement with findings from more general digital literacy research suggesting that younger students struggle, relatively speaking, with digital literacy tasks requiring critical thinking and have no apparent advantage with skills requiring strategic engagement (Eshet-Alkalai \& Chajut, 2009; van Deursen \& van Dijk, 2011). Participant 10 described the challenge like this:

I have students straight out of college who hate technology because their only experience of it is the worst elements... They never learned how to be a part of real conversations. They never learned how to shape relationships right, and so they are deeply almost scarred by it, right?

Indeed, this instructor believes the most important literacy for any student is the need to bring participant-centered convening and facilitating skills to bear on practices of online engagement. Participant 8 also identified this more sociocultural dimension as a place where instructors need to spend more time with their younger students:

It's not "Let me teach you how to do this." ... I know you're in five social networks. We'd love to learn what you're doing, but can we talk about some best practices around just social interaction? So the general formation of particularly younger students as future leaders, as present leaders, and faith leaders-and then just the social care of other people around you-has always been there for seminaries, but we need to attend to it on social networks as well.

Connected to this need particularly for social formation, Participant 8 also talked about wanting students to be more critical about the connection between theology and media theory. While stressing that the pattern is not absolute, she noted that "younger students are more comfortable with the computers that they're carrying around in their pockets than the older students" (see Theme 1 above) but that instructors need to "complexify" their understanding of these early-career students and "not to romanticize that they understand what they're doing." For Participant 8 , such understanding is primarily about how social media logic is shaping patterns of religious community, about "learning those habits of thinking theologically about these new landscapes." Participant 36 spoke about his own earlier experience as a somewhat unreflective practitioner in a way consistent with Participant 8's characterization:

I think as a young minster, there were times where we spent an extraordinary amount of energy on the digital tools and on being present to that space without a lot of critical reflection about what 
we were seeking to accomplish or what we were actually [doing]. I think assessment is a big part of that. It's a big part of being honest with yourself about what you're doing when you're there.

Returning now to the JD-R framework, we can see this theme as a kind of mirror image of the previous one. Theme 1 represents the tendency for older students not to have had direct experience navigating online spaces - which for younger students tends to be a built-in personal resource that can be leveraged professionally. Moreover, older students are likely to experience anxiety about experimenting, which adds to the personal demands of their learning experience. By contrast, Theme 2 speaks to younger students' tendency to be less experienced leaders/conveners of conversations and integrators of theory and action. Consider Participant 10's subsequent elaboration about the relative unimportance of technology per se in the literacies she views as most important:

so the skills I want for seminarians may not sound at all like digital tech, but they are prompted by an environment that if you can learn how to be an agile listener ... [that will] stand you in a really good stead, whatever space you're in.

Here technological sophistication per se is not as relevant, so the experiential advantage younger students often bring to the navigating and experimenting literacies by virtue of past digital immersion is lessened. On the other hand, older students with more substantial experience leading communities, negotiating interpersonal relationships, and reflecting critically on their professional practice may have substantial and relevant resources on which they can draw to master the convening and reflecting literacies.

This second theme resonates with the work of a student we will call Daniel. Daniel was a few years out of college, and his class project was to build a website intended to serve as a resource for people conducting a certain kind of specialized ministry. As his work continued, it became clear that he saw the site in a way we have seen many students and practitioners (of all ages) frame their work. With apologies to Tolkien, Oliver has come to refer to this temptation as "one site to rule them all." As in, "I want to create the go-to resource for everyone who wants to know about [this topic]."

Oliver and his co-instructor attempted to connect Daniel with other people doing similar work in this specialized ministry area and with colleagues from his region of the U.S. We thought his effort would benefit greatly from such exposure and focus, but we were not very successful in helping him shape the trajectory of the project in ways that were sustainable and would put him in meaningful conversation with colleagues. Our final feedback on his project reflects our frustration:

We continue to think this [site] can only be effective and sustained for a more targeted, regional audience ... We would love for you to be involved with the several efforts already in place in [our 
denomination's] circles and beyond ... to curate a larger, more authoritative collection of such resources.

Of course, Daniel had the right to build his website however he liked. Moreover, the trouble with convening conversations and integrating a religious tradition's theological beliefs with one's media analysis is that both these tasks take a lot of time. In Daniel's case, it is likely that the demands of producing a professionally useful website site were beyond the time, energy, and motivation he had available for this project. When viewed in light of the JD-R framework, this can be understood as an imbalance of job demands and resources.

Daniel's story reminds us to "complexify" (Participant 8) our view of earlycareer students and create opportunities for them to practice receiving and integrating feedback on their convening and reflecting skills as they develop as ministers and digital communicators. This caution can deliver us from the temptation to treat them as technology whiz kids who can pick up any skill by experimentation and create any media infrastructure our communities need without significant training, feedback, or time to develop as practitioners. Like mid- and late-career students, we need to meet younger students where their resources and demands strike the kind of balance that leads to a challenging and productive learning experience. Older students usually recognize quite easily what they don't know, because the resources they have available aren't sufficient for their full participation in online communities. They get frustrated right away, and that frustration is important information for their learning. The demands that stress our younger students as online leaders may not be so obvious to them. The fact that Daniel did not need our help to get a website up and running did not mean his site would help him meet his strategic ministry goals in the long run. In such cases, it may be our job as instructors to be quite firm and honest in anticipating our students' likely future frustration when they learn that not all the literacies are equally challenging for all students.

\section{CLOSING REFLECTIONS \& FUTURE WORK}

This exploratory analysis of the DLM framework through the life-span lens of the JD-R model represents a small but important step in better understanding the media literacy education needs and opportunities facing adults of different age and career stages in graduate theological education and other professional school contexts. Together with our domain-specific digital literacy tasks - or analogous frameworks from other fields - we believe the theoretical apparatus of the job demands-resources model is especially promising for interpreting observed behavior and for pedagogical planning that helps students more explicitly identify both their strengths and their challenges. We have shown how a JD-R lens, as operationalized by Salmela-Aro and Upadyaya (2018) across life-span and the personal-professional divide, can sharpen our thinking about how to support and challenge diverse adult students.

Moreover, as this article has occasioned our re-immersion in colleagues' reflections on their teaching practice, we have become increasingly intrigued by the 
question of what it means for adult practitioners in any field to be socialized into online communities popularly understood as youth- and young adult-oriented or dominated. As reported above, many of the transcript excerpts Oliver originally coded as age-related focused on learning to reach a younger audience online. To the extent that this framing is accurate, it raises the question of how mid- and latecareer professionals participate authentically in digital cultures. And since we know the youth-oriented framing is reductive, it also raises the trickier question of how older students - and the older educators teaching in professional schools - can claim the DLM insight and authority their experiences have given them.

We believe the primary significance of our findings is pedagogical: They serve to redirect instructor and student attention from the operational details of technology tools to the overlapping nexus of context and experience. On the one hand, the context of digital literacy practice invites learners to reconsider who might possess, or be able to develop, various kinds of technologically mediated communication and leadership skills and why these skills are important in the first place. On the other hand, stressing personal and professional experience rather than age better reflects what digital divide scholars have come to believe is the variable that matters most and provides a jumping-off point for explicitly negotiating and pursing appropriate individual learning objectives. Of course, the themes and cases we identified also suggest a range of possible literacy-specific instructional practices, which we outline in Table 5.

Table 5

Implications of Analysis for Instructors Seeking to Help Age-diverse Students to Develop DLM

\begin{tabular}{ll}
\hline Career stage & Pedagogical approaches \\
\hline Early-career & $\begin{array}{l}\text { Create opportunities for students to practice gathering and } \\
\text { leading online conversations (convening) }\end{array}$ \\
& $\begin{array}{l}\text { Scaffold student reflection to better connect values of faith } \\
\text { tradition to digital media practice (reflecting) }\end{array}$ \\
Mid- and & $\begin{array}{l}\text { Scaffold guided introductions to unfamiliar social media } \\
\text { platforms and practices (navigating) }\end{array}$ \\
& $\begin{array}{l}\text { Create low-risk opportunities for students to practice using } \\
\text { tools that are new to them (experimenting) }\end{array}$ \\
\hline
\end{tabular}

The obvious limitation of this paper's analysis is the small sample and anecdotal character of instructors' (and our own) reports of student learning. Still, our interview sample represented our best knowledge of the small number of colleagues engaging in media literacy education in theological education, and the study is to our knowledge the most comprehensive undertaken to date of this 
fledgling subfield of practical theology. Our participants are influential leaders in this emerging community of practice, and we believe the connections they made between domain-specific digital literacies and how students of different ages go about developing them, however partial and tentative, warrant more direct empirical study.

Our research team's ongoing inquiry in this area will likely provide opportunities for both qualitative and quantitative testing of these tentative conclusions. As of this writing, we have just begun a study in which instructors across the seminary curriculum are, with the help of a digital literacies coach, incorporating assignments intended to help students develop one or more of the DLM. Our research protocol includes collection and multimodal analysis of student artifacts. This study will give us our best opportunity yet to "compare apples to apples" as learners of different ages work to develop the same literacies according to the same assignment and same classroom supports.

As for quantitative measures, we have developed a survey instrument that will allow ministry practitioners and trainees to self-report their beliefs about, and strengths and weaknesses with, each of the seven literacies. Age is one of several demographic factors we collect. We have begun piloting this survey as a standalone instrument and as a student pre- and post-test for participants in courses whose instructors are adopting the DLM framework. Although student age and career stage is not the primary analytical lens we are bringing to these studies, the occasion of this article and special issue have certainly focused our interest on attending to age and career stage as we continue exploring what it means to train for professional practice in the age of new media.

\section{REFERENCES}

Association of Theological Schools. (2006). Recent data reflect a younger student body. Theological Education, 14(5), 1.

Bakker, A. B., \& Demerouti, E. (2007). The job demands-resources model: State of the art. Journal of Managerial Psychology, 22(3), 309-328.

Bayne, S., \& Ross, J. (2007, December). The 'digital native' and 'digital immigrant': A dangerous opposition. Paper presented at the Annual Conference of the Society for Research into Higher Education, Brighton, UK. Retrieved from http://www.academia.edu/download/4963108/natives final.pdf

Bennett, S., \& Maton, K. (2010). Beyond the "digital natives" debate: Towards a more nuanced understanding of students' technology experiences. Journal of Computer Assisted Learning, 26(5), 321-331.

Bradburn, N. M., Sudman, S., \& Wansink, B. (2004). Asking questions (2nd edition). San Francisco, CA: Jossey-Bass.

Brown, C., \& Czerniewicz, L. (2010). Debunking the "digital native": Beyond digital apartheid, towards digital democracy. Journal of Computer Assisted Learning, 26(5), 357-369.

Campbell, H. A. (2012). Understanding the relationship between religion online and offline in a networked society. Journal of the American Academy of 
Religion, 80(1), 64-93.

Cheong, P. H. (2011). Religious leaders, mediated authority, and social change. Journal of Applied Communication Research, 39(4), 452-454.

Copeland, A. J. (2015). Writing digitally. In E. D. Barreto (Ed.), Writing theologically (pp. 87-102). Minneapolis, MN: Augsburg Fortress.

Corbin, B., Colditz, J., Switzer, G., Sidani, J., Klatt, P., Schaffer, T., \& Primack, B. (2018). The SMARxT media literacy program: Improving evidencebased prescribing among medical students. Journal of Media Literacy Education, 10(3), 1-19.

Cubbage, J., Gillians, P., Algood, C., \& Ramsey, V. S. (2017). Implementing media literacy training for social work programs at HBCUs. Journal of Human Behavior in the Social Environment, 27(5), 498-513.

Eshet-Alkalai, Y., \& Chajut, E. (2009). Changes over time in digital literacy. CyberPsychology \& Behavior, 12(6), 713-715.

Foster, C. R., Dahill, L., Golemon, L., \& Tolentino, B. W. (2005). Educating clergy: Teaching practices and pastoral imagination. San Francisco: Jossey-Bass.

Friemel, T. N. (2016). The digital divide has grown old: Determinants of a digital divide among seniors. New Media \& Society, 18(2), 313-331.

Herzberger, S. (2008). Nursing media-educated patients. Journal for Nurses in Professional Development, 24(3), 101-104.

Hess, M. E. (2005). Engaging technology in theological education. Lanham, MD: Sheed \& Ward.

Hollander, J. A. (2004). The social contexts of focus groups. Journal of Contemporary Ethnography, 33(5), 602-637.

Jenkins, H., Purushotma, R., Weigel, M., Clinton, K., \& Robison, A. J. (2009). Confronting the challenges of participatory culture. Cambridge, MA: MIT Press.

Jewitt, C. (2005). Multimodality, "reading," and "writing" for the 21 st century. Discourse: Studies in the cultural politics of education, 26(3), 315-331.

Jones, C., Ramanau, R., Cross, S., \& Healing, G. (2010). Net generation or Digital Natives: Is there a distinct new generation entering university? Computers \& Education, 54(3), 722-732.

Kivunja, C. (2014). Do you want your students to be job-ready with 21 st century skills? Change pedagogies. International Journal of Higher Education, $3(3), 81$.

Lankshear, C., \& Knobel, M. (Eds.). (2008). Digital literacies: Concepts, policies and practices. New York, NY: Peter Lang.

Leander, K. M., \& Vasudevan, L. (2009). Multimodality and mobile culture. In C. Jewitt (Ed.), The Routledge handbook of multimodal analysis (pp. 127139). New York, NY: Routledge.

Livingstone, S., \& Helsper, E. (2007). Gradations in digital inclusion: Children, young people and the digital divide. New Media \& Society, 9(4), 671-696.

Lytle, J. A. (2013). Faith formation 4.0. New York, NY: Morehouse.

Malony, H. N., \& Hunt, R. A. (1991). The psychology of clergy. Harrisburg, PA: Morehouse Publishing. 
Martin, A., \& Grudziecki, J. (2006). DigEuLit: Concepts and tools for digital literacy development. Innovation in Teaching and Learning in Information and Computer Sciences, 5(4), 1-19.

Mitchell, P. (2011). Digital literacy and the spaces of academic discourse. In P. T. Trifonas (Ed.), Learning the virtual life: Public pedagogy in a digital world (pp. 1-14). New York, NY: Routledge.

Nesbitt, P. D. (1995). First and second-career clergy: Influences of age and gender on the career-stage paradigm. Journal for the Scientific Study of Religion, 34(2), 152-171.

Nichols, R. C. (2018). Pastoral leadership for the small, rural church: The second career pastor (Unpublished doctoral dissertation). George Fox University, Portland, OR.

Noy, C. (2008). Sampling knowledge: The hermeneutics of snowball sampling in qualitative research. International Journal of Social Research Methodology, 11(4), 327-344.

Oliver, K. M. (2019). Networked religion meets digital geographies: Pedagogical principles for exploring new spaces and roles in the seminary classroom. Teaching Theology \& Religion, 22(1), 3-15.

Oliver, K. M., Kimball, E. M., Williams-Duncan, S., \& Blanchard, I. (2016, November). Digital media for ministry asset mapping: An exploratory study in theological education. Poster presented at Religious Education Association Annual Meeting, Pittsburgh, PA. Retrieved from https://religiouseducation.net/papers/rea2016-oliver1.pdf

Oliver, K. M., Williams-Duncan, S., \& Kimball, E. M. (2019). Digital literacies for ministry: A qualitative study of theological educators preparing students for new media engagement. Manuscript submitted for publication.

Pew Research Center. (2014). Religion and electronic media. Retrieved from http://www.pewforum.org/2014/11/06/religion-and-electronic-media/

Pew Research Center. (2015). U.S. public becoming less religious. Retrieved from http://www.pewforum.org/2015/11/03/u-s-public-becoming-less-religious

Prensky, M. (2001). Digital natives, digital immigrants. On the Horizon, 9(5), 16.

Price-Dennis, D., Holmes, K. A., \& Smith, E. (2015). Exploring digital literacy practices in an inclusive classroom. The Reading Teacher, 69(2), 195-205.

Putnam, R. D. (2000). Bowling alone. New York, NY: Simon and Schuster.

Rainie, L., \& Wellman, B. (2012) Networked: The new social operating system. Cambridge, MA: MIT Press.

Salmela-Aro, K., \& Upadyaya, K. (2018). Role of demands-resources in work engagement and burnout in different career stages. Journal of Vocational Behavior, 108, 190-200.

Schaufeli, W. B. (2017). Applying the job demands-resources model. Organizational Dynamics, 46(2), 120-132.

Schreurs, K., Quan-Haase, A., \& Martin, K. (2017). Problematizing the digital literacy paradox in the context of older adults' ICT use. Canadian Journal of Communication, 42(2), 359-377. 
Sheehy, M., \& Leander, K. (2004). Introduction. In K. Leander \& Sheehy, Margaret (Eds.), Spatializing literacy research and practice (pp. 1-13). New York, NY: Peter Lang.

van Deursen, A., \& van Dijk, J. (2011). Internet skills and the digital divide. New Media \& Society, 13(6), 893-911.

van Dijk, J. A. (2005). The deepening divide: Inequality in the information society. Thousand Oaks, CA: Sage Publications.

Vasudevan, L. (2010). Education remix: New media, literacies, and the emerging digital geographies. Digital Culture \& Education, 2(1), 62-82.

Voogt, J., Erstad, O., Dede, C., \& Mishra, P. (2013). Challenges to learning and schooling in the digital networked world of the 21st century. Journal of Computer Assisted Learning, 29(5), 403-413.

Wells, C. R., Probst, J., McKeown, R., Mitchem, S., \& Whiejong, H. (2012). The relationship between work-related stress and boundary-related stress within the clerical profession. Journal of Religion and Health, 51(1), 215230 .

Zsupan-Jerome, D. (2014). Connected toward communion. Collegeville, MN: Liturgical Press. 